See discussions, stats, and author profiles for this publication at: https://www.researchgate.net/publication/276065116

\title{
A comparative study of the effects of different low-level lasers on the proliferation, viability, and migration of human melanocytes in vitro
}

Article in Lasers in Medical Science · May 2015

DOI: 10.1007/s10103-015-1758-x · Source: PubMed

CITATIONS

8

4 authors, including:

Khalid M Alghamdi

King Saud University

75 PUBLICATIONS 920 CITATIONS

SEE PROFILE

Abdelkader Ashour

2. Kulliyyah of Medicine, International Islamic University Malaysia

78 PUBLICATIONS 716 CITATIONS

SEE PROFILE

Some of the authors of this publication are also working on these related projects:

Effect of thymoquinone on human hepatocellular carcinoma View project

IQGAP1 RNAi View project
Ashok Kumar

King Saud University

31 PUBLICATIONS 390 CITATIONS

SEE PROFILE 


\title{
A comparative study of the effects of different low-level lasers on the proliferation, viability, and migration of human melanocytes in vitro
}

\author{
Khalid M. AlGhamdi ${ }^{1,2}$ • Ashok Kumar ${ }^{2}$ - Abdelkader E. Ashour ${ }^{3}$. \\ Attieh A. AlGhamdi ${ }^{4}$
}

Received: 25 October 2014 / Accepted: 23 April 2015

(C) Springer-Verlag London 2015

\begin{abstract}
The aim of this study was to investigate the effects of different low-level laser therapies (LLLTs) of various wavelengths and energies on normal cultured human melanocytes. Various studies have shown the effects of LLLs on various types of cultured cells. Presently, little is known about the biological effects of LLLTs on melanocytes. Melanocytes were exposed to LLLT at $0.5,1.0,1.5,2.0,2.5,3.0,3.5,4.0$, 4.5 , or $5.0 \mathrm{~J} / \mathrm{cm}^{2}$ using a blue $(457 \mathrm{~nm})$, red $(635 \mathrm{~nm})$, or ultraviolet (UV) $(355 \mathrm{~nm})$ laser. Melanocyte viability, proliferation, and migration were monitored at $72 \mathrm{~h}$ after irradiation. The blue $(P<0.001)$ and red $(P<0.001$ and $P<0.01)$ lasers significantly enhanced viability at 0.5 to $2.0 \mathrm{~J} / \mathrm{cm}^{2}$, whereas the UV laser $(P<0.001)$ could significantly enhance viability only at 0.5 and $1.0 \mathrm{~J} / \mathrm{cm}^{2}$ compared with controls. The blue and red lasers also significantly enhanced the proliferation of the melanocytes at 0.5 to $2.0 \mathrm{~J} / \mathrm{cm}^{2}(P<0.001)$, and the UV laser significantly enhanced proliferation at 0.5 to $1.5 \mathrm{~J} / \mathrm{cm}^{2}$ $(P<0.001$ and $P<0.01)$ compared with controls. The blue laser significantly enhanced melanocyte migration at 0.5 to $4.0 \mathrm{~J} / \mathrm{cm}^{2}(P<0.001$ to $P<0.05)$, but the red $(P<0.001$ and $P<0.01)$ and UV $(P<0.001$ to $P<0.05)$ lasers could significantly enhance such migration at 0.5 to $1.0 \mathrm{~J} / \mathrm{cm}^{2}$ and 0.5 to
\end{abstract}

Khalid M. AlGhamdi

kmgderm@gmail.com

1 Department of Dermatology, College of Medicine, King Saud University, P.O. Box 240997, Riyadh 11322, Saudi Arabia

2 Vitiligo Research Chair, College of Medicine, King Saud University, Riyadh, Saudi Arabia

3 Department of Pharmacology and Toxicology, College of Pharmacy, King Saud University, Riyadh, Saudi Arabia

4 Center of Nanotechnology, King Abdulaziz University, Jeddah, Saudi Arabia
$2.0 \mathrm{~J} / \mathrm{cm}^{2}$, respectively, compared with controls. LLLT at low energy densities is able to significantly increase melanocyte viability, proliferation, and migration in vitro, and at higher energy densities, it gives non-stimulatory results. Additionally, the blue laser was the best among the three lasers. These findings might have potential application in vitiligo treatment in future.

Keywords Low-level laser therapy · Cell culture · Viability · Proliferation $\cdot$ Melanocytes $\cdot$ Tissue engineering ·

Regenerative medicine

\section{Introduction}

Vitiligo is a common depigmentation disorder occurring in approximately $1 \%$ of the world's population [1]. It appears as white patches on the skin due to a loss of functioning epidermal melanocytes.

Due to the obscure pathogenesis of the disease, the treatment options for vitiligo are generally unsatisfactory and difficult. In addition, patients who do respond are at risk for relapse [2, 3]. Therefore, there is a strong need for new therapeutic repigmentation modalities for the treatment of vitiligo.

Low-level laser therapy (LLLT) is a fast-growing technology used to treat a multitude of conditions. This therapy is widely applied in different branches of regenerative medicine, such as tissue regeneration [4] and dentistry, in which it is used to enhance the healing process [5]. Currently, LLLT is considered to be a reliable tool to enhance the proliferation of various cell lines [6-8] and stem cells [9]. Additionally, it has been reported that LLLT can increase skin pigmentation by stimulating melanocyte proliferation [2]. However, only one report has shown that using a red laser in LLLT can enhance 
melanocyte proliferation [10]. In addition, the comparative effects of different LLLs on melanocytes have not yet been reported. Therefore, the purpose of the present study was to compare the effects of LLLT using different lasers (red, blue, and ultraviolet (UV)) and energy densities on human melanocyte viability, proliferation, and migration.

\section{Materials and methods}

\section{Melanocyte isolation and culture}

This study has been approved by the ethical committee of the College of Medicine of King Saud University. The melanocytes used in this study were obtained from normal human foreskin. A biopsy was washed thrice with sterile phosphatebuffered saline (PBS) and cut into small pieces $(5 \times 5 \mathrm{~mm})$. The tissue samples were then placed in PBS containing $2.5 \%$ trypsin solution, followed by incubation at $37^{\circ} \mathrm{C}$ for $1 \mathrm{~h}$. The epidermal sheets were next separated from the dermal face, and the epidermal cells were released by vigorous pipetting. The suspended cells were harvested by centrifugation ( $200 \mathrm{~g}$, $5 \mathrm{~min}$, at room temperature) and were seeded in two $25-\mathrm{cm}^{2}$ tissue culture flasks containing a melanocyte growthpromoting medium (Gibco, Grand Island, NY, USA) and incubated at $37{ }^{\circ} \mathrm{C}$ in a humidified atmosphere containing $5 \%$ $\mathrm{CO}_{2}$, as described by Lerner et al. with slight modifications [11]. The melanocyte growth-promoting medium was changed after $24 \mathrm{~h}$ of seeding so that free-floating cells were removed. Subsequently, the medium was changed regularly (every 2 days). Approximately 7 to 10 days after primary seeding, semi-confluent cells were harvested by incubation with $0.25 \%$ trypsin and $0.01 \%$ ethylenediaminetetraacetic acid (EDTA) solution (Sigma, St. Louis, MO, USA) at $37^{\circ} \mathrm{C}$ for 3 to $5 \mathrm{~min}$. The reaction was stopped using soybean solution (Sigma). The cells were centrifuged at $500 \mathrm{~g}$ for $5 \mathrm{~min}$, and the cell pellet was then resuspended and incubated in culture medium. Third- to sixth-passage cells were used in the following experiments.

\section{LLL irradiation}

Different previously published irradiation methods were used to irradiate the melanocytes $[9,10,12-15]$. The experimental setup of the current study is shown in Fig. 1, in which all output laser beams were from three types of polarized continuous wave (CW) diode lasers: a blue laser $(\lambda=457 \mathrm{~nm})$, a red laser $(\lambda=635 \mathrm{~nm})$, and a UV laser $(\lambda=355 \mathrm{~nm})$ passed through an optical fiber coupler connected to one optical fiber. The far end of this 2-m optical fiber was held by an XYZ arm and easily brought to the culture cell plates for three differentcolored (blue, red, and UV) irradiations. Each laser was supported by a beam block, a natural density filter, and two coated mirrors to control the wavelength, output power, and alignment of the beams, respectively. The transmitted mirror (TM) 1 reflected the UV laser beam only, whereas TM2 transmitted the UV laser beam and reflected the red laser beam. Additionally, TM3 transmitted the UV and red laser beams
Fig. 1 Schematic diagram of the LLLT experimental setup. TM1, TM2, and TM3 are transmitted mirrors. $N D$ natural density

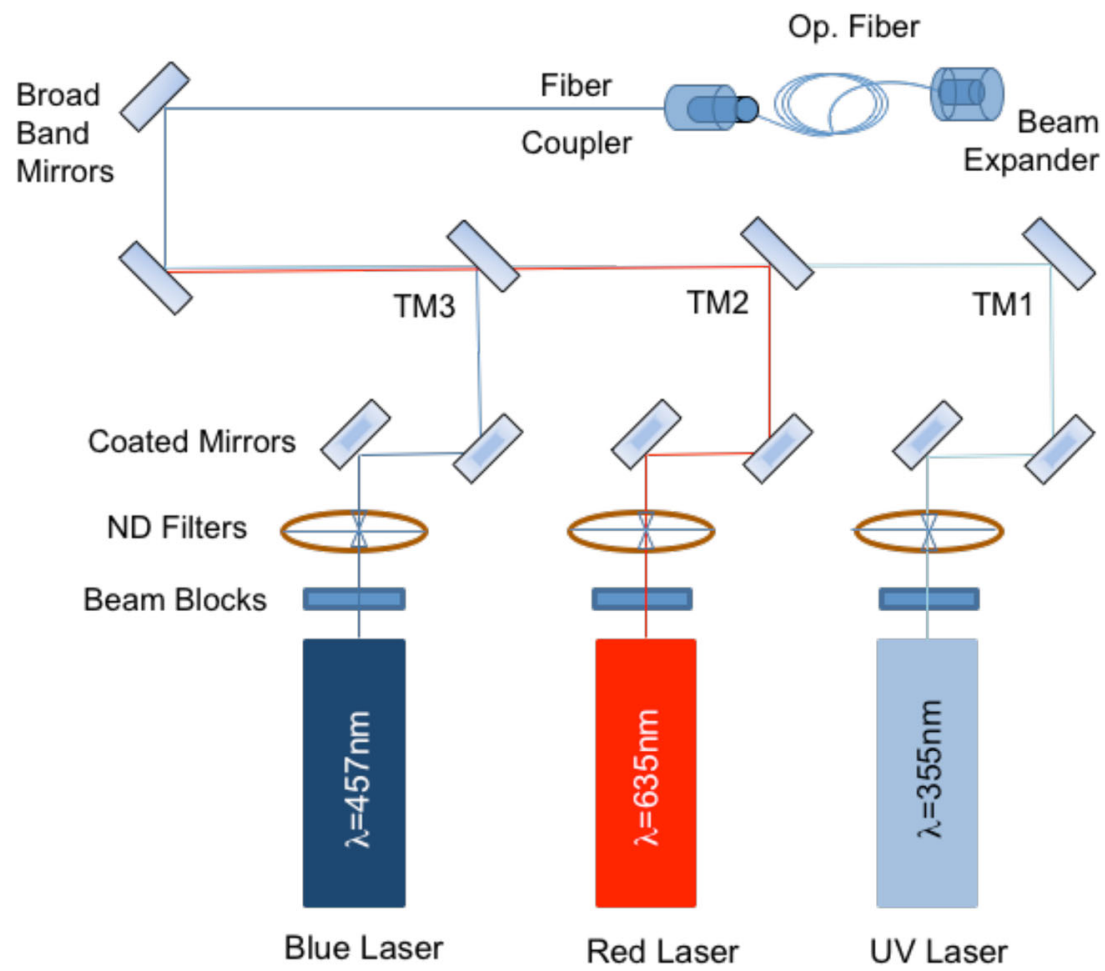


and reflected the blue laser beam. All colors were directed to the fiber coupler with two broadband mirrors.

The laser beams were delivered by the optical fiber, and the power density output was kept constant at $25 \mathrm{~mW} / \mathrm{cm}^{2}$ in the $\mathrm{CW}$ mode in all experiments because it had been optimal for the photobiostimulation of cell proliferation in other cell cultures in our laboratory. The fiber end was brought to a certain distance from the cell culture plate, such that a $10-\mathrm{mm}$ - diameter laser beam equally covered the surface of each well in the 48-well plate with a controllable energy density. Prior to lasing, the average energy at the end of the fiber was determined using an energy meter (Gentec, SOLO 2 (R2), Canada). Melanocytes were seeded onto the 48 -well plates at a density of $4 \times 10^{4}$ cells per well and were incubated overnight. The medium of the melanocytes was replaced with sterile PBS to minimize the loss of laser energy through absorption by the
Fig. 2 Effects of blue (a), red (b), and UV laser (c) irradiation on the viability of normal cultured human melanocytes $72 \mathrm{~h}$ following exposure. Significance of differences between irradiated cells and controls: $* P<0.05$;

$* * P<0.01 ; * * * P<0.001$

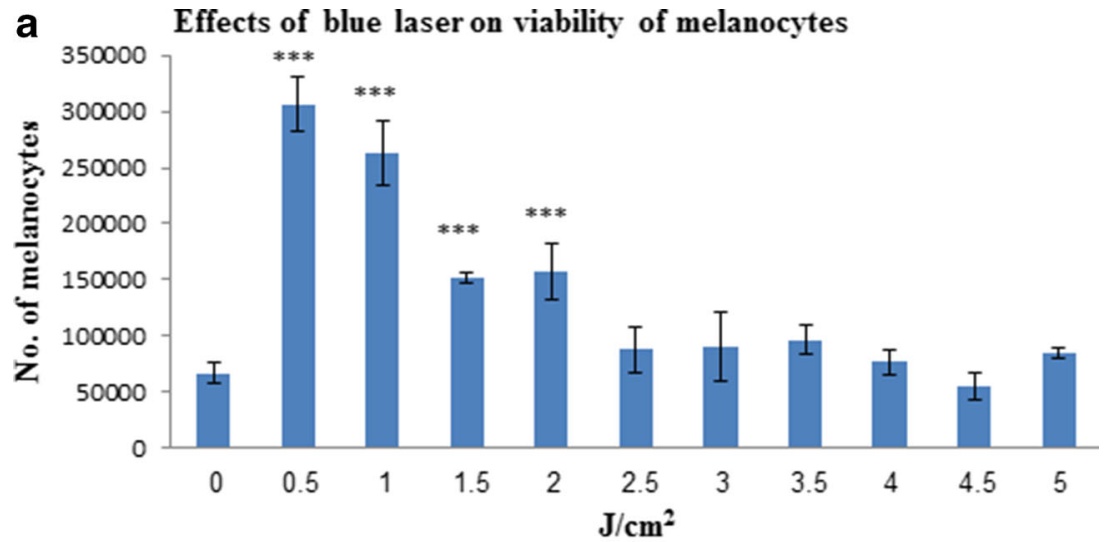

b Effects of red laser on viability of melanocytes
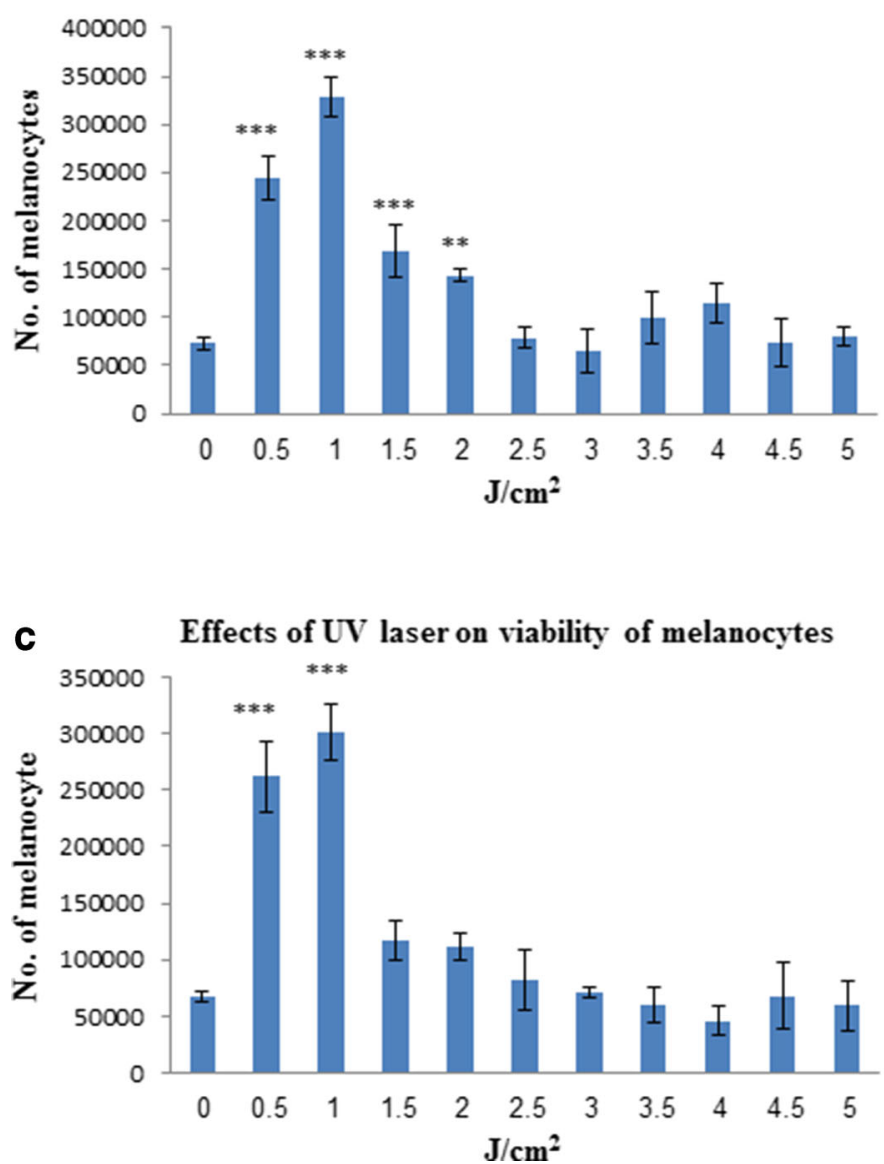
colored culture medium. The melanocytes were irradiated only once with the blue, red, or UV laser at an energy density of $0.5,1.0,1.5,2.0,2.5,3.0,3.5,4.0,4.5$, or $5.0 \mathrm{~J} / \mathrm{cm}^{2}$ for 20 to $200 \mathrm{~s}$. Next, along with control groups (non-irradiated), the cells were incubated for $72 \mathrm{~h}$. The formula used for calculating the designated duration of laser treatment was as follows: time $(\mathrm{sec})=$ energy $\left(\mathrm{J} / \mathrm{cm}^{2}\right) \times$ surface area $\left(\mathrm{cm}^{2}\right) /$ power $(W)[16]$. During the experiments, one well was irradiated at a time, whereas all other wells stayed protected from direct light by black tape. To protect the cells from irradiation scattering, each seeded well was surrounded with empty neighboring wells. To avoid the influence of second-order variables, the cells in all experimental groups, including the control groups, were exposed to the same environmental and stress conditions, such as temperature, humidity, and light. Plastic-topped plates were used, and sterile culture conditions were maintained. After irradiation, the PBS was replaced with fresh melanocyte growth-promoting medium for further incubation as described above. The irradiation procedure was performed at room temperature and was performed in partial darkness, with the laser as the only light source. All irradiation experiments were performed in triplicate, and the average numbers of melanocytes were used for analysis.

\section{Cell viability}

The effect of LLLT on the melanocyte viability was assessed using a trypan blue exclusion assay. At the end of the irradiation and the $72 \mathrm{~h}$ of incubation, the melanocytes were washed with PBS and harvested by gentle trypsinization (0.25\% trypsin- $0.01 \%$ EDTA suspension; Gibco) in a constant volume of $0.1 \mathrm{ml}$, followed by mixing with an equal volume of trypan blue (Sigma). The solution was incubated for $5 \mathrm{~min}$ and loaded into a hemocytometer counting chamber, and the total number of cells, the number of viable (unstained) cells, and the number of nonviable (stained) cells per milliliter were counted to determine the $\%$ viability [17]. The $\%$ viability was defined as the number of viable cells (translucent)/the total cell number $\times 100$. Three separate counts were performed for each well. The number of cells was counted and compared with that of non-irradiated controls, and graphs were plotted for cell viability.

\section{Cell proliferation determination}

The effect of LLLT on melanocyte proliferation was assessed using a 3-[4,5-dimethylthiazol-2-yl]-2,5-diphenyltetrazolium bromide (MTT) assay-based cell growth determination kit (Sigma, cat no. CGD-1). Irradiated and non-irradiated melanocytes were incubated with $10 \%$ MTT solution for $3 \mathrm{~h}$ at $37^{\circ} \mathrm{C}$. The MTT solution was then replaced with an equal volume of isopropanol. The plates were next incubated with shaking for $45 \mathrm{~min}$ at room temperature. The absorbance was then read at $549 \mathrm{~nm}$ using an $\mathrm{EL} \times 800$ counter (Universal Microplate Reader, BioTek Instruments, USA).

Table 1 Significant values obtained from one-way ANOVA assessment of the means of three cell culture experiments examining the viability of melanocytes treated with LLLT

\begin{tabular}{|c|c|c|c|}
\hline \multirow{2}{*}{$\begin{array}{l}\text { Doses of low-level laser } \\
\text { therapy }\end{array}$} & \multicolumn{3}{|l|}{$P$ value } \\
\hline & Blue laser & Red laser & Ultraviolet laser \\
\hline Control vs. $0.5 \mathrm{~J} / \mathrm{cm}^{2}$ & $<0.001$ & $<0.001$ & $<0.001$ \\
\hline Control vs. $1.0 \mathrm{~J} / \mathrm{cm}^{2}$ & $<0.001$ & $<0.001$ & $<0.001$ \\
\hline Control vs. $1.5 \mathrm{~J} / \mathrm{cm}^{2}$ & $<0.001$ & $<0.001$ & $>0.05$ \\
\hline Control vs. $2.0 \mathrm{~J} / \mathrm{cm}^{2}$ & $<0.001$ & $<0.01$ & $>0.05$ \\
\hline 0.5 vs. $1.0 \mathrm{~J} / \mathrm{cm}^{2}$ & $>0.05$ & $<0.001$ & $>0.05$ \\
\hline 0.5 vs. $1.5 \mathrm{~J} / \mathrm{cm}^{2}$ & $<0.001$ & $<0.01$ & $<0.001$ \\
\hline 0.5 vs. $2.0 \mathrm{~J} / \mathrm{cm}^{2}$ & $<0.001$ & $<0.001$ & $<0.001$ \\
\hline 0.5 vs. $2.5 \mathrm{~J} / \mathrm{cm}^{2}$ & $<0.001$ & $<0.001$ & $<0.001$ \\
\hline 0.5 vs. $3.0 \mathrm{~J} / \mathrm{cm}^{2}$ & $<0.001$ & $<0.001$ & $<0.001$ \\
\hline 0.5 vs. $3.5 \mathrm{~J} / \mathrm{cm}^{2}$ & $<0.001$ & $<0.001$ & $<0.001$ \\
\hline 0.5 vs. $4.0 \mathrm{~J} / \mathrm{cm}^{2}$ & $<0.001$ & $<0.001$ & $<0.001$ \\
\hline 0.5 vs. $4.5 \mathrm{~J} / \mathrm{cm}^{2}$ & $<0.001$ & $<0.001$ & $<0.001$ \\
\hline 0.5 vs. $5.0 \mathrm{~J} / \mathrm{cm}^{2}$ & $<0.001$ & $<0.001$ & $<0.001$ \\
\hline 1.0 vs. $1.5 \mathrm{~J} / \mathrm{cm}^{2}$ & $<0.001$ & $<0.001$ & $<0.001$ \\
\hline 1.0 vs. $2.0 \mathrm{~J} / \mathrm{cm}^{2}$ & $<0.001$ & $<0.001$ & $<0.001$ \\
\hline 1.0 vs. $2.5 \mathrm{~J} / \mathrm{cm}^{2}$ & $<0.001$ & $<0.001$ & $<0.001$ \\
\hline 1.0 vs. $3.0 \mathrm{~J} / \mathrm{cm}^{2}$ & $<0.001$ & $<0.001$ & $<0.001$ \\
\hline 1.0 vs. $3.5 \mathrm{~J} / \mathrm{cm}^{2}$ & $<0.001$ & $<0.001$ & $<0.001$ \\
\hline 1.0 vs. $4.0 \mathrm{~J} / \mathrm{cm}^{2}$ & $<0.001$ & $<0.001$ & $<0.001$ \\
\hline 1.0 vs. $4.5 \mathrm{~J} / \mathrm{cm}^{2}$ & $<0.001$ & $<0.001$ & $<0.001$ \\
\hline 1.0 vs. $5.0 \mathrm{~J} / \mathrm{cm}^{2}$ & $<0.001$ & $<0.001$ & $<0.001$ \\
\hline 1.5 vs. $2.0 \mathrm{~J} / \mathrm{cm}^{2}$ & $>0.05$ & $>0.05$ & $>0.05$ \\
\hline 1.5 vs. $2.5 \mathrm{~J} / \mathrm{cm}^{2}$ & $<0.05$ & $<0.001$ & $>0.05$ \\
\hline 1.5 vs. $3.0 \mathrm{~J} / \mathrm{cm}^{2}$ & $<0.05$ & $<0.001$ & $>0.05$ \\
\hline 1.5 vs. $3.5 \mathrm{~J} / \mathrm{cm}^{2}$ & $>0.05$ & $<0.01$ & $>0.05$ \\
\hline 1.5 vs. $4.0 \mathrm{~J} / \mathrm{cm}^{2}$ & $<0.01$ & $<0.05$ & $<0.01$ \\
\hline 1.5 vs. $4.5 \mathrm{~J} / \mathrm{cm}^{2}$ & $<0.001$ & $<0.001$ & $>0.05$ \\
\hline 1.5 vs. $5.0 \mathrm{~J} / \mathrm{cm}^{2}$ & $<0.05$ & $<0.001$ & $<0.05$ \\
\hline 2.0 vs. $2.5 \mathrm{~J} / \mathrm{cm}^{2}$ & $<0.01$ & $<0.01$ & $>0.05$ \\
\hline 2.0 vs. $3.0 \mathrm{~J} / \mathrm{cm}^{2}$ & $<0.05$ & $<0.001$ & $>0.05$ \\
\hline 2.0 vs. $3.5 \mathrm{~J} / \mathrm{cm}^{2}$ & $<0.05$ & $>0.05$ & $>0.05$ \\
\hline 2.0 vs. $4.0 \mathrm{~J} / \mathrm{cm}^{2}$ & $<0.01$ & $>0.05$ & $<0.05$ \\
\hline 2.0 vs. $4.5 \mathrm{~J} / \mathrm{cm}^{2}$ & $<0.001$ & $<0.01$ & $>0.05$ \\
\hline 2.0 vs. $5.0 \mathrm{~J} / \mathrm{cm}^{2}$ & $<0.01$ & $<0.01$ & $>0.05$ \\
\hline
\end{tabular}

The statistical data were obtained for melanocytes irradiated with different lasers of different LLL energies and for controls (no irradiation or $0.0 \mathrm{~J} / \mathrm{cm}^{2}$ ) using one-way ANOVA and the post hoc Tukey HSD test. Energy densities of $2.5 \mathrm{~J} / \mathrm{cm}^{2}$ onward were not included, as their effects on melanocytes were not statistically significant relative to controls 


\section{Cell migration assay}

The effect of LLLT on the migration of melanocytes was assessed using the in vitro scratch assay described by Liang et al. with slight modifications [18]. Briefly, melanocytes were seeded and incubated overnight. A "scratch" was then created in a cell monolayer with the help of a sterile 200 - $\mu$ l pipette tip, after which the cells were irradiated as described above. Debris from the cells was removed by changing the medium, and the cells were incubated at $37^{\circ} \mathrm{C}$. Images were captured at $0,24,48$, and $72 \mathrm{~h}$ to monitor the migration of the cells to close the scratch. Photographs were taken using a chargecoupled device camera attached to an inverted phasecontrast microscope (Olympus, Tokyo, Japan) at a power of $\times 10$. For statistical analyses, images were taken from three separate "scratch areas" under the same magnification. The images were compared with controls. Additionally, the numbers of migrated melanocytes were counted in the "scratch
Fig. 3 The MTT assay was used to determine the proliferation effects of blue (a), red (b), and UV lasers (c) from 0.5 to $5.0 \mathrm{~J} / \mathrm{cm}^{2}$ on the proliferation of normal cultured human melanocytes $72 \mathrm{hrs}$ following exposure. Significance of differences between irradiated cells and controls: ${ }^{*} P<0.05$;

$* * P<0.01 ; * * * P<0.001$ a

Effects of blue laser on proliferation of melanocytes

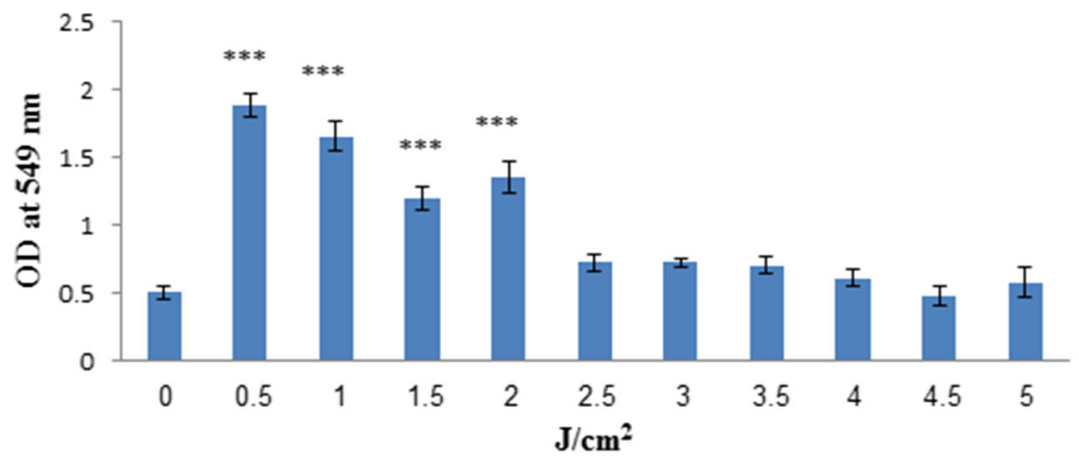

b

Effects of red laser on proliferation of melanocytes

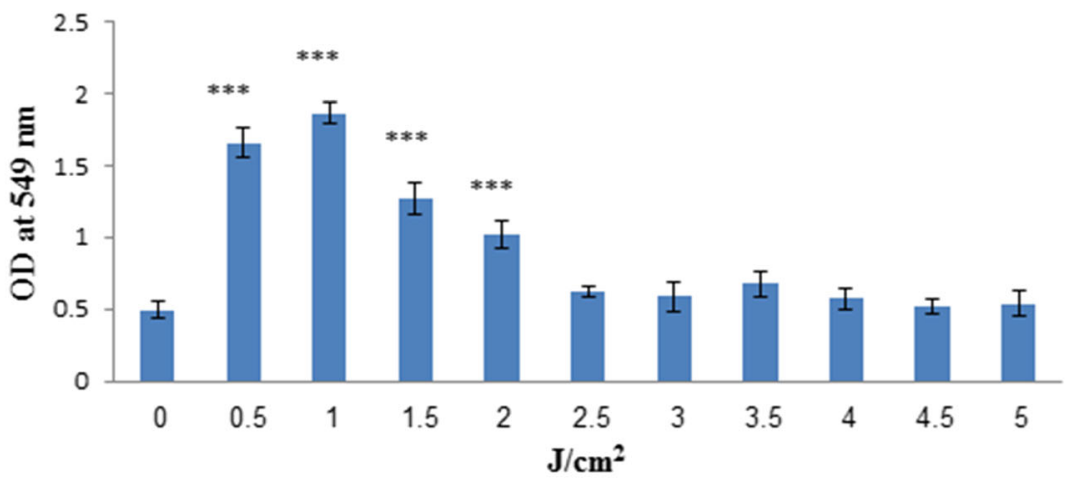

C Effects of UV laser on proliferation of melanocytes

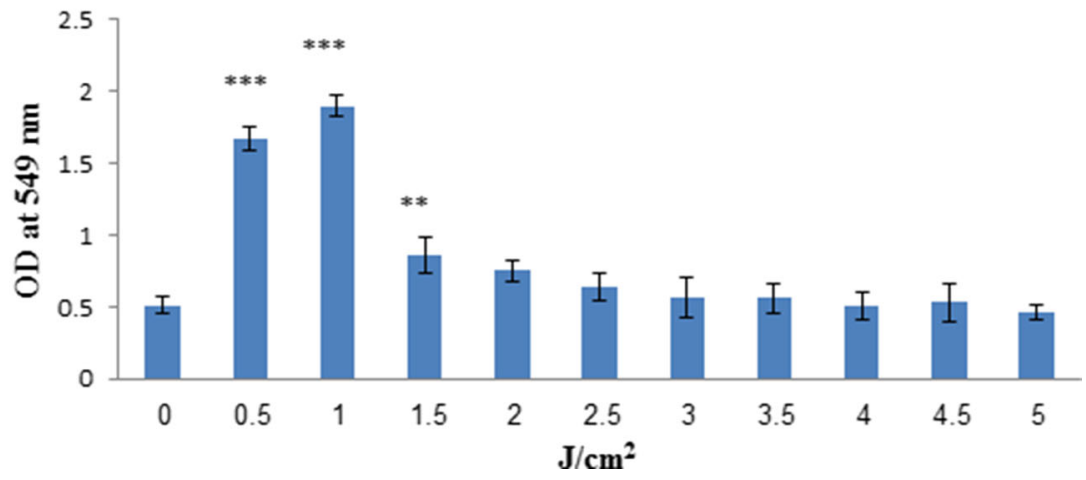


area," and graphs were plotted for cell migration. All assays were performed in triplicate on at least two separate occasions.

\section{Statistical analysis}

One-way analysis of variance (ANOVA) was used to compare the mean values of quantitative variables across the categorical variables, followed by the post hoc Tukey HSD test, which was used to verify whether there were any significant differences between the different laser-treated groups and the controls. A $P$ value $<0.05$ was considered as statistically significant. The data were analyzed using GraphPad Prism 4.0 (GraphPad Software, San Diego, CA, USA) statistical software.

\section{Results}

\section{LLLT enhanced viability of cultured melanocytes}

As illustrated in Fig. 2, a single exposure of cultured melanocytes to a blue, red, or UV laser promoted their viability in an energy density-dependent manner relative to their controls. In this study, the percentage of cells was determined at $72 \mathrm{~h}$ following irradiation. The blue laser significantly increased the number of melanocytes (Fig. 2a) by 4.6-, 3.95-, 2.26-, and 2.35-fold in wells exposed to 0.5, 1.0, 1.5, and $2.0 \mathrm{~J} / \mathrm{cm}^{2}$, respectively, compared with controls, with a maximal and significant effect obtained following $0.5 \mathrm{~J} / \mathrm{cm}^{2}$ irradiation $(P<0.001)$. From 2.5 to $5.0 \mathrm{~J} / \mathrm{cm}^{2}$, except $4.5 \mathrm{~J} / \mathrm{cm}^{2}$, the blue laser failed to significantly increase the number of melanocytes compared with controls. The red laser significantly increased the number of melanocytes (Fig. 2b) by 3.38-, 4.52-, 2.32-, and 1.98-fold in wells exposed to $0.5,1.0,1.5$, and $2.0 \mathrm{~J} / \mathrm{cm}^{2}$, respectively, compared with controls, with a maximal and significant effect obtained following $1.0 \mathrm{~J} / \mathrm{cm}^{2}$ irradiation $(P<0.001)$. However, at energy densities from 2.5 to $5.0 \mathrm{~J} / \mathrm{cm}^{2}$ (except $4.0 \mathrm{~J} / \mathrm{cm}^{2}$ ), the red laser failed to significantly increase the number of melanocytes relative to controls. The UV laser significantly increased the number of melanocytes (Fig. 2c) by 3.92- and 4.52-fold in wells exposed to 0.5 and $1.0 \mathrm{~J} / \mathrm{cm}^{2}$, respectively. However, at energy densities from 1.5 to $5.0 \mathrm{~J} / \mathrm{cm}^{2}$, the UV laser did not significantly increase the number of melanocytes relative to controls.

When one-way ANOVA analysis was performed within groups exposed to different energy densities, it was observed that at an energy density of $0.5 \mathrm{~J} / \mathrm{cm}^{2}$, the blue laser significantly increased the number of melanocytes compared with the blue laser at 1.5 to $5.0 \mathrm{~J} / \mathrm{cm}^{2}$, with a $P$ value $<0.001$. Similarly, at an energy density of $1.0 \mathrm{~J} / \mathrm{cm}^{2}$, the blue laser significantly increased the number of melanocytes compared with the blue laser at 1.5 to $5.0 \mathrm{~J} / \mathrm{cm}^{2}$, with a $P$ value $<0.001$. The red and UV lasers at energy densities of 0.5 and $1.0 \mathrm{~J} / \mathrm{cm}^{2}$ significantly increased the number of melanocytes compared with the other energy densities used in the study (Table 1).

Table 2 Significant values obtained from one-way ANOVA assessment of the means of three cell culture experiments examining the proliferation of melanocytes treated with LLLT

\begin{tabular}{|c|c|c|c|}
\hline \multirow{2}{*}{$\begin{array}{l}\text { Doses of low-level laser } \\
\text { therapy }\end{array}$} & \multicolumn{3}{|l|}{$P$ value } \\
\hline & Blue laser & Red laser & Ultraviolet laser \\
\hline Control vs. $0.5 \mathrm{~J} / \mathrm{cm}^{2}$ & $<0.001$ & $<0.001$ & $<0.001$ \\
\hline Control vs. $1.0 \mathrm{~J} / \mathrm{cm}^{2}$ & $<0.001$ & $<0.001$ & $<0.001$ \\
\hline Control vs. $1.5 \mathrm{~J} / \mathrm{cm}^{2}$ & $<0.001$ & $<0.001$ & $<0.01$ \\
\hline Control vs. $2.0 \mathrm{~J} / \mathrm{cm}^{2}$ & $<0.001$ & $<0.001$ & $>0.05$ \\
\hline 0.5 vs. $1.5 \mathrm{~J} / \mathrm{cm}^{2}$ & $<0.001$ & $<0.001$ & $<0.001$ \\
\hline $0.5 \mathrm{vs} .2 .0 \mathrm{~J} / \mathrm{cm}^{2}$ & $<0.001$ & $<0.001$ & $<0.001$ \\
\hline 0.5 vs. $2.5 \mathrm{~J} / \mathrm{cm}^{2}$ & $<0.001$ & $<0.001$ & $<0.001$ \\
\hline $0.5 \mathrm{vs} .3 .0 \mathrm{~J} / \mathrm{cm}^{2}$ & $<0.001$ & $<0.001$ & $<0.001$ \\
\hline $0.5 \mathrm{vs} .3 .5 \mathrm{~J} / \mathrm{cm}^{2}$ & $<0.001$ & $<0.001$ & $<0.001$ \\
\hline $0.5 \mathrm{vs} .4 .0 \mathrm{~J} / \mathrm{cm}^{2}$ & $<0.001$ & $<0.001$ & $<0.001$ \\
\hline 0.5 vs. $4.5 \mathrm{~J} / \mathrm{cm}^{2}$ & $<0.001$ & $<0.001$ & $<0.001$ \\
\hline 0.5 vs. $5.0 \mathrm{~J} / \mathrm{cm}^{2}$ & $<0.001$ & $<0.001$ & $<0.001$ \\
\hline 1.0 vs. $1.5 \mathrm{~J} / \mathrm{cm}^{2}$ & $<0.001$ & $<0.001$ & $<0.001$ \\
\hline 1.0 vs. $2.0 \mathrm{~J} / \mathrm{cm}^{2}$ & $<0.05$ & $<0.001$ & $<0.001$ \\
\hline 1.0 vs. $2.5 \mathrm{~J} / \mathrm{cm}^{2}$ & $<0.001$ & $<0.001$ & $<0.001$ \\
\hline 1.0 vs. $3.0 \mathrm{~J} / \mathrm{cm}^{2}$ & $<0.001$ & $<0.001$ & $<0.001$ \\
\hline 1.0 vs. $3.5 \mathrm{~J} / \mathrm{cm}^{2}$ & $<0.001$ & $<0.001$ & $<0.001$ \\
\hline $1.0 \mathrm{vs} .4 .0 \mathrm{~J} / \mathrm{cm}^{2}$ & $<0.001$ & $<0.001$ & $<0.001$ \\
\hline 1.0 vs. $4.5 \mathrm{~J} / \mathrm{cm}^{2}$ & $<0.001$ & $<0.001$ & $<0.001$ \\
\hline 1.0 vs. $5.0 \mathrm{~J} / \mathrm{cm}^{2}$ & $<0.001$ & $<0.001$ & $<0.001$ \\
\hline $1.5 \mathrm{vs} .2 .0 \mathrm{~J} / \mathrm{cm}^{2}$ & $>0.05$ & $>0.05$ & $>0.05$ \\
\hline 1.5 vs. $2.5 \mathrm{~J} / \mathrm{cm}^{2}$ & $<0.001$ & $<0.001$ & $>0.05$ \\
\hline $1.5 \mathrm{vs} .3 .0 \mathrm{~J} / \mathrm{cm}^{2}$ & $<0.001$ & $<0.001$ & $<0.05$ \\
\hline $1.5 \mathrm{vs} .3 .5 \mathrm{~J} / \mathrm{cm}^{2}$ & $<0.001$ & $<0.001$ & $<0.01$ \\
\hline $1.5 \mathrm{vs} .4 .0 \mathrm{~J} / \mathrm{cm}^{2}$ & $<0.001$ & $<0.001$ & $<0.01$ \\
\hline $1.5 \mathrm{vs} .4 .5 \mathrm{~J} / \mathrm{cm}^{2}$ & $<0.001$ & $<0.001$ & $<0.01$ \\
\hline $1.5 \mathrm{vs} .5 .0 \mathrm{~J} / \mathrm{cm}^{2}$ & $<0.001$ & $<0.001$ & $<0.001$ \\
\hline 2.0 vs. $2.5 \mathrm{~J} / \mathrm{cm}^{2}$ & $<0.001$ & $<0.01$ & $>0.05$ \\
\hline 2.0 vs. $3.0 \mathrm{~J} / \mathrm{cm}^{2}$ & $<0.001$ & $<0.001$ & $>0.05$ \\
\hline 2.0 vs. $3.5 \mathrm{~J} / \mathrm{cm}^{2}$ & $<0.001$ & $<0.01$ & $>0.05$ \\
\hline 2.0 vs. $4.0 \mathrm{~J} / \mathrm{cm}^{2}$ & $<0.001$ & $<0.001$ & $<0.05$ \\
\hline 2.0 vs. $4.5 \mathrm{~J} / \mathrm{cm}^{2}$ & $<0.001$ & $<0.001$ & $>0.05$ \\
\hline 2.0 vs. $5.0 \mathrm{~J} / \mathrm{cm}^{2}$ & $<0.001$ & $<0.001$ & $<0.05$ \\
\hline
\end{tabular}

The statistical data were obtained for melanocytes irradiated with different lasers of different LLL energies and for controls (no irradiation, or $0.0 \mathrm{~J} / \mathrm{cm}^{2}$ ) using one-way ANOVA and the post hoc Tukey HSD test. Energy densities of $2.5 \mathrm{~J} / \mathrm{cm}^{2}$ onward were not included, as their effects on melanocytes were not statistically significant relative to controls 


\section{LLLT enhanced proliferation of cultured melanocytes}

The MTT assay, which is based on mitochondrial activity, showed a significant increase in the proliferation of melanocytes treated with LLLT. The blue laser enhanced proliferation by 3.74-, 3.28-, 2.37-, and 2.69-fold at energy densities of 0.5 , $1.0,1.5$, and $2.0 \mathrm{~J} / \mathrm{cm}^{2}$, respectively, compared with controls, with a maximal and significant effect obtained following $0.5 \mathrm{~J} / \mathrm{cm}^{2}$ irradiation $(P<0.001)$. However, the blue laser could not increase the proliferation of melanocytes significantly when the melanocytes were treated at energy densities from 2.5 to $5.0 \mathrm{~J} / \mathrm{cm}^{2}$ (Fig. 3a). The red laser significantly increased the proliferation of melanocytes (Fig. 3b) by 3.35-, 3.77-, 2.56-, and 2.05-fold in wells exposed to 0.5, 1.0, 1.5, and $2.0 \mathrm{~J} / \mathrm{cm}^{2}$, respectively, compared with controls, with a maximal and significant effect obtained following $1.0 \mathrm{~J} / \mathrm{cm}^{2}$ irradiation $(P<0.001)$. At energy densities from 2.5 to $5.0 \mathrm{~J} / \mathrm{cm}^{2}$, the red laser could not significantly increase the proliferation of melanocytes. Proliferation was enhanced by 3.27-, 3.7-, and 1.68-fold when melanocytes were treated with the UV laser at energy densities of $0.5,1.0$, and $1.5 \mathrm{~J} / \mathrm{cm}^{2}$, respectively, compared with controls, with a maximal and significant effect obtained following
$1.0 \mathrm{~J} / \mathrm{cm}^{2}$ irradiation $(P<0.001)$. However, at energy densities from 2.0 to $5.0 \mathrm{~J} / \mathrm{cm}^{2}$, the UV laser did not significantly enhance melanocyte proliferation relative to controls (Fig. 3c).

One-way ANOVA within groups showed that the blue and red lasers at energy densities from 0.5 to $2.0 \mathrm{~J} / \mathrm{cm}^{2}$ significantly increased the proliferation of melanocytes compared with the other energy densities used in the study, and the lowest $P$ value was $<0.05$. Moreover, the UV laser at energy densities of 0.5 and $1.0 \mathrm{~J} / \mathrm{cm}^{2}$ enhanced melanocyte proliferation compared with the other energy densities used in the study (Table 2).

\section{LLLT enhanced migration of cultured melanocytes}

The number of migrated melanocytes treated with LLLT was significantly higher compared with controls. The number of melanocytes treated with the blue laser at energy densities from 0.5 to $4.0 \mathrm{~J} / \mathrm{cm}^{2}$ was significantly increased compared with controls, with a maximal and significant effect obtained following 0.5 or $1.0 \mathrm{~J} / \mathrm{cm}^{2}$ irradiation $(P<0.001)$ (Fig. $\left.4 \mathrm{a}\right)$. In contrast, the red laser could significantly enhance the migration of melanocytes only at energy densities of 0.5 and $1.0 \mathrm{~J} / \mathrm{cm}^{2}$ compared with controls, with a maximal and significant effect obtained following $1.0 \mathrm{~J} / \mathrm{cm}^{2}$ irradiation

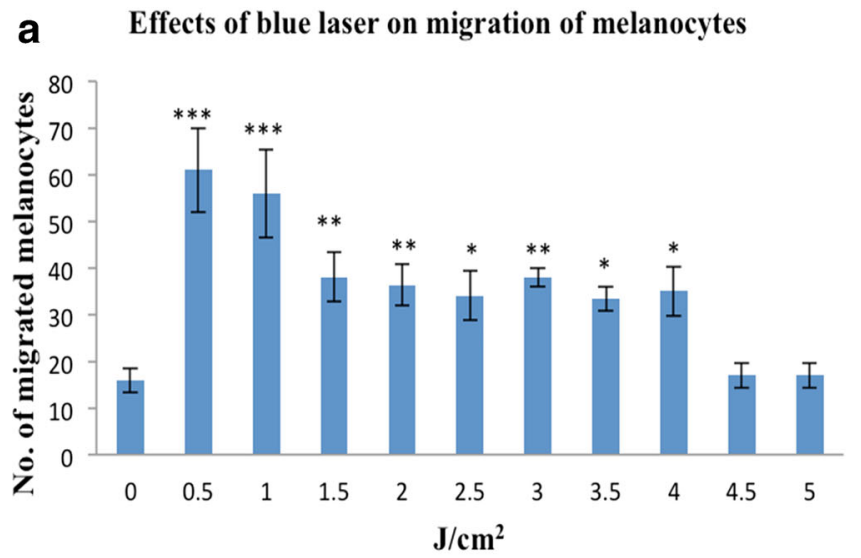

b Effects of red laser on migration of melanocytes

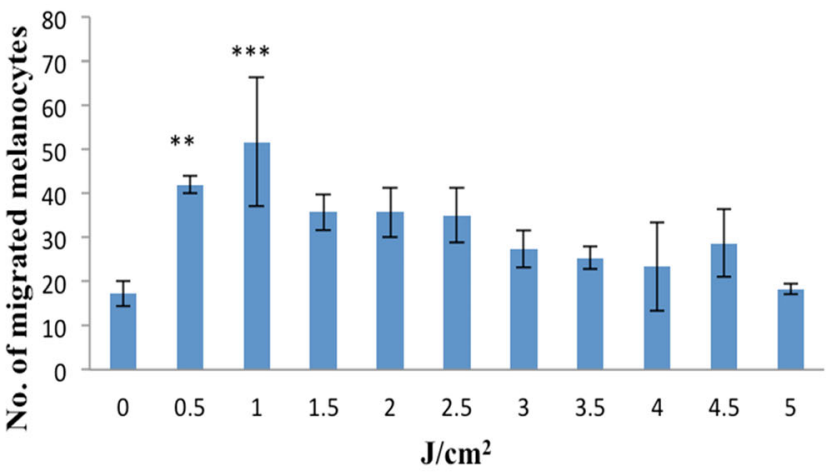

C Effects of UV laser on migration of melanocytes

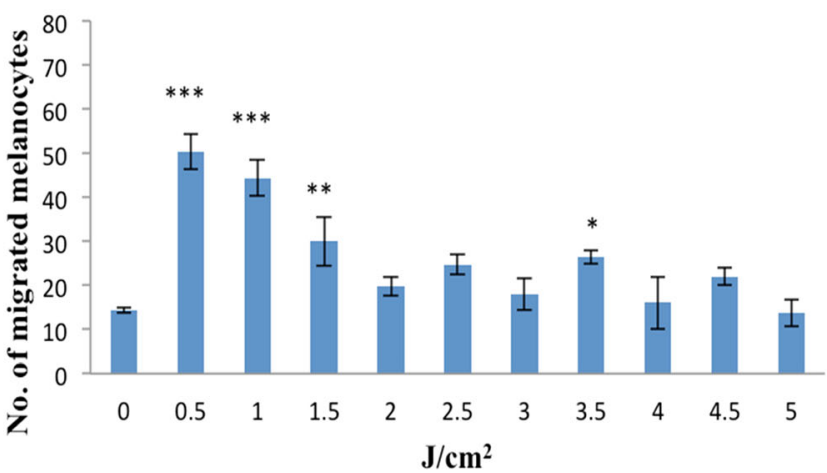

Fig. 4 A scratch assay was used to determine the effect of blue (a), red (b), and UV lasers (c) from 0.5 to $5.0 \mathrm{~J} / \mathrm{cm}^{2}$ on the migration of normal cultured human melanocytes $72 \mathrm{hrs}$ following exposure. Significance of differences between irradiated cells and controls: ${ }^{*} P<0.05 ;{ }^{* *} P<0.01 ;{ }^{* * *} P<0.001$ 
$(P<0.001)$. However, at energy densities from 1.5 to $5.0 \mathrm{~J} / \mathrm{cm}^{2}$, the red laser failed to significantly increase the migration of melanocytes relative to controls (Fig. 4b). The UV laser significantly enhanced the migration of melanocytes at energy densities of 0.5 and $1.5 \mathrm{~J} / \mathrm{cm}^{2}$ compared with controls, with a maximal and significant effect obtained following 0.5 or $1.0 \mathrm{~J} / \mathrm{cm}^{2}$ irradiation $(P<0.001)$. Interestingly, $3.5 \mathrm{~J} / \mathrm{cm}^{2}$ showed significant enhancement in the migration of melanocytes, with a $P$ value $<0.05$. However, at energy densities from 2.0 to 3.0 and from 4.0 to $5.0 \mathrm{~J} / \mathrm{cm}^{2}$, the UV laser failed to significantly increase the migration of melanocytes compared with controls (Fig. 4c). Photomicrographs showed that the blue laser was significantly more effective than the other lasers were at an energy density of $0.5 \mathrm{~J} / \mathrm{cm}^{2}$ compared with controls in enhancing the migration of melanocytes (Fig. 5).

One-way ANOVA within groups of different energy densities showed that at energy densities from 0.5 to $1.0 \mathrm{~J} / \mathrm{cm}^{2}$, the blue and UV lasers significantly increased melanocyte migration compared with the other energy densities used in the study, with a $P$ value $<0.05$. In contrast, the red laser did not significantly affect melanocyte migration compared with controls when the analysis was performed within groups of different energy densities (Table 3).

\section{Discussion}

LLLT is known to stimulate the proliferation and differentiation of several types of cells, including fibroblasts and stem cells $[8,9,19]$. LLLT is a type of photomodulation that uses photons to modulate biological activity. During LLLT, light is absorbed by a photoreceptor, and a chain of molecular actions is started that directs the photoactivation of enzymes in the mitochondria, signal transduction, and amplification, ending with a photoresponse [20]. LLLT is absorbed by components of the respiratory chain, which leads to changes in both the mitochondria and the cytoplasm. During the LLLT process, additional $\mathrm{Ca}^{2+}$ transported into the cytoplasm, which triggers mitosis and modulates DNA and RNA synthesis at LLL doses, in turn modulating and enhancing cell proliferation. At higher LLL doses, too much $\mathrm{Ca}^{2+}$ is released, which exhausts the ATP reserves of the cell [21].

A variety of factors influence the LLLT process [22]. Selection of the correct wavelength, the duration of irradiation, the power density $\left(\mathrm{W} / \mathrm{cm}^{2}\right)$, and the type of cell irradiated is important to obtain maximum biostimulation from LLLT $[23,24]$. Additionally, constant application of the correct dose is required if the best therapeutic effects are to be achieved, as
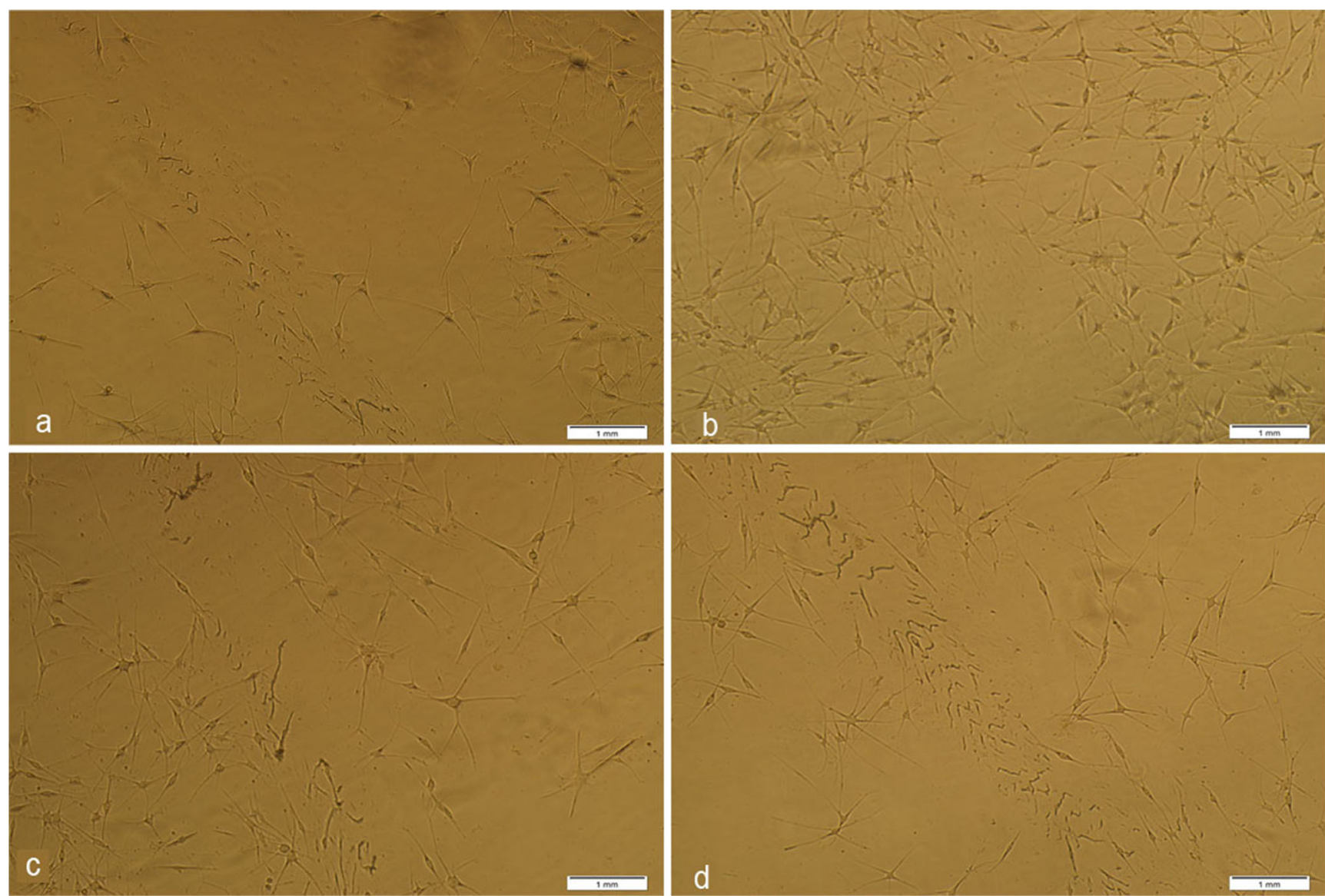

Fig. 5 Photomicrograph of normal cultured human melanocytes showing migration after $72 \mathrm{~h}$ of LLLT at an energy density of $0.5 \mathrm{~J} / \mathrm{cm}^{2}$. Non-irradiated melanocytes (a), melanocytes treated with a blue laser (b), melanocytes treated with a red laser (c), and melanocytes treated with a UV laser (d) 
Table 3 Significant values obtained from one-way ANOVA assessment of the means of three cell culture experiments examining the migration of melanocytes treated with LLLT

\begin{tabular}{|c|c|c|c|}
\hline \multirow{2}{*}{$\begin{array}{l}\text { Doses of low-level laser } \\
\text { therapy }\end{array}$} & \multicolumn{3}{|l|}{$P$ value } \\
\hline & Blue laser & Red laser & Ultraviolet laser \\
\hline Control vs. $0.5 \mathrm{~J} / \mathrm{cm}^{2}$ & $<0.001$ & $<0.01$ & $<0.001$ \\
\hline Control vs. $1.0 \mathrm{~J} / \mathrm{cm}^{2}$ & $<0.001$ & $<0.001$ & $<0.001$ \\
\hline Control vs. $1.5 \mathrm{~J} / \mathrm{cm}^{2}$ & $<0.01$ & $>0.05$ & $<0.01$ \\
\hline Control vs. $2.0 \mathrm{~J} / \mathrm{cm}^{2}$ & $<0.01$ & $>0.05$ & $>0.05$ \\
\hline Control vs. $2.5 \mathrm{~J} / \mathrm{cm}^{2}$ & $<0.05$ & $>0.05$ & $>0.05$ \\
\hline Control vs. $3.0 \mathrm{~J} / \mathrm{cm}^{2}$ & $<0.01$ & $>0.05$ & $>0.05$ \\
\hline Control vs. $3.5 \mathrm{~J} / \mathrm{cm}^{2}$ & $<0.05$ & $>0.05$ & $<0.05$ \\
\hline Control vs. $4.0 \mathrm{~J} / \mathrm{cm}^{2}$ & $<0.05$ & $>0.05$ & $>0.05$ \\
\hline 0.5 vs. $1.0 \mathrm{~J} / \mathrm{cm}^{2}$ & $>0.05$ & $>0.05$ & $>0.05$ \\
\hline 0.5 vs. $1.5 \mathrm{~J} / \mathrm{cm}^{2}$ & $<0.01$ & $>0.05$ & $<0.001$ \\
\hline 0.5 vs. $2.0 \mathrm{~J} / \mathrm{cm}^{2}$ & $<0.001$ & $>0.05$ & $<0.001$ \\
\hline 0.5 vs. $2.5 \mathrm{~J} / \mathrm{cm}^{2}$ & $<0.001$ & $>0.05$ & $<0.001$ \\
\hline 0.5 vs. $3.0 \mathrm{~J} / \mathrm{cm}^{2}$ & $<0.01$ & $>0.05$ & $<0.001$ \\
\hline 0.5 vs. $3.5 \mathrm{~J} / \mathrm{cm}^{2}$ & $<0.001$ & $>0.05$ & $<0.001$ \\
\hline 0.5 vs. $4.0 \mathrm{~J} / \mathrm{cm}^{2}$ & $<0.001$ & $>0.05$ & $<0.001$ \\
\hline 0.5 vs. $4.5 \mathrm{~J} / \mathrm{cm}^{2}$ & $<0.001$ & $>0.05$ & $<0.001$ \\
\hline 0.5 vs. $5.0 \mathrm{~J} / \mathrm{cm}^{2}$ & $<0.001$ & $<0.05$ & $<0.001$ \\
\hline 1.0 vs. $1.5 \mathrm{~J} / \mathrm{cm}^{2}$ & $<0.05$ & $>0.05$ & $<0.01$ \\
\hline 1.0 vs. $2.0 \mathrm{~J} / \mathrm{cm}^{2}$ & $<0.05$ & $>0.05$ & $<0.001$ \\
\hline 1.0 vs. $2.5 \mathrm{~J} / \mathrm{cm}^{2}$ & $<0.01$ & $>0.05$ & $<0.001$ \\
\hline 1.0 vs. $3.0 \mathrm{~J} / \mathrm{cm}^{2}$ & $<0.05$ & $<0.01$ & $<0.001$ \\
\hline 1.0 vs. $3.5 \mathrm{~J} / \mathrm{cm}^{2}$ & $<0.01$ & $<0.01$ & $<0.001$ \\
\hline 1.0 vs. $4.0 \mathrm{~J} / \mathrm{cm}^{2}$ & $<0.01$ & $<0.01$ & $<0.001$ \\
\hline 1.0 vs. $4.5 \mathrm{~J} / \mathrm{cm}^{2}$ & $<0.001$ & $<0.05$ & $<0.001$ \\
\hline 1.0 vs. $5.0 \mathrm{~J} / \mathrm{cm}^{2}$ & $<0.001$ & $<0.001$ & $<0.001$ \\
\hline
\end{tabular}

The statistical data were obtained for melanocytes irradiated with different lasers of different LLL energies and for controls (no irradiation or $0.0 \mathrm{~J} / \mathrm{cm}^{2}$ ) using one-way ANOVA and the post hoc Tukey HSD test. Energy densities of $2.5 \mathrm{~J} / \mathrm{cm}^{2}$ onward were not included, as their effects on melanocytes were not statistically significant relative to controls

this parameter plays the most important role in both the stimulation and the inhibition of cellular metabolism [6]. The design of the LLLT protocol used in the present study was based on our previously published extensive review [6].

The initial aim of this study was to determine irradiation parameters leading to the enhanced proliferation of melanocytes following low-level blue, red, or UV laser irradiation and to examine the viability, proliferation, and migration of melanocytes after treatment. In this study, for the first time, the effects of three different lasers and exposure times on melanocytes were examined.

Viability and proliferation are essential biological parameters for any cells, including melanocytes. To determine the viability and proliferation of LLL-irradiated melanocytes, trypan blue staining and the MTT assay were used, respectively [17]. Pinheiro et al. recommended lower doses of LLLT to irradiate mucosal and skin wounds because the absorption and spreading of light are greater due to the lack of an optical barrier [25]. High doses of LLLT reduce biostimulatory effects and damage photoreceptors due to the inhibition of metabolism and consequent cell death $[23,26]$. Therefore, in the present study, melanocytes were treated with low and high doses of blue, red, and UV lasers, as the objectives were to stimulate the proliferation of melanocytes and to observe the negative effects of high doses. We observed that the blue and red lasers significantly increased the viability and proliferation of melanocytes at lower doses $\left(0.5\right.$ to $\left.2.0 \mathrm{~J} / \mathrm{cm}^{2}\right)$, whereas higher doses showed non-stimulatory effects. In contrast, the UV laser showed positive effects only at 0.5 and $1.0 \mathrm{~J} / \mathrm{cm}^{2}$. Wavelengths of 600 to $700 \mathrm{~nm}$ were used to stimulate cell proliferation [27]. Our results also showed that the red laser at $635 \mathrm{~nm}$ helped to increase the viability and proliferation of melanocytes. In addition, LLLT showed a dosedependent effect in the present study. The above results indicate induction of the mitochondrial activity and proliferation of LLL-irradiated melanocytes compared with the controls. The graphs, photomicrographs, and tables support these results (Figs. 1, 2, 3, 4, and 5 and Tables 1, 2, and 3).

Migration is critical to the function of melanocytes. Human melanocytes are known to originate from the neural crest and then to migrate to colonize the basal layer of the epidermis [28]. Functional melanocytes are destroyed in vitiliginous skin, whereas inactive melanocytes are spared [29]. Following various forms of vitiligo therapy, including phototherapy, inactive melanocytes could be recruited to repigment the vitiliginous macules [30, 31]. Repigmentation starts as a result of the proliferation of the inactive melanocytes, followed by their migration to the nearby epidermis to form small pigmentation islands that expand and coalesce to form normally pigmented skin $[32,33]$. The "scratch assay" is a convenient, straightforward, and inexpensive method to study cell migration in vitro [18]. One of the major advantages of this simple method is that it mimics the migration of cells in vivo to a certain extent. In the present study, the blue laser ( 0.5 to $\left.4.0 \mathrm{~J} / \mathrm{cm}^{2}\right)$, red laser $\left(0.5\right.$ and $\left.1.0 \mathrm{~J} / \mathrm{cm}^{2}\right)$, and UV laser $(0.5$ to $1.5 \mathrm{~J} / \mathrm{cm}^{2}$ ) significantly increased melanocyte migration. We observed that the blue laser was more effective in enhancing melanocyte migration compared with the red and UV lasers (Figs. 4 and 5 and Table 3). These results conform with earlier reports [34].

Phase-contrast microscopy was used to demonstrate melanocyte migration into the center of "scratch areas" in control and LLL-treated melanocytes (Fig. 5). The migration of melanocytes across the central scratch was also a good indicator of cell proliferation. LLL appeared to improve the functions, maintain the viability, and increase the proliferation of melanocytes so that they avidly migrated across the central scratch. This behavior could be extrapolated 
to the in vivo milieu, possibly serving as an attempt to distribute melanin pigment in all parts of the skin, with consequently high potential for the treatment of recalcitrant vitiligo.

The enhancement of melanocyte viability, proliferation, and migration by LLLT has medical significance. In light of the present study, it is worth proposing that in vitiligo patients, LLLT can augment melanocyte proliferation and migration and thus may rescue damaged melanocytes and stimulate inactive melanocytes by providing the proper microenvironment to increase their growth and, in turn, their repigmentation efficiency. In this experiment, we have used normal cultured human melanocytes; therefore, this might not be applicable in vitiligo the same way it does in our experiment. As melanocytes in skin are in a complex environment, where signals from cell-to-cell contact, paracrine signals, ambient light, inflammation (especially in vitiligo), etc. may alter the behavior of melanocytes, which is totally different from in vitro. Therefore, similar results seen in this in vitro study may not be replicated same way in vivo. However, LLLT can be a useful therapeutic option for vitiligo management and other skin diseases, which deserve further studies.

There were no obvious harmful effects noticed in treated patients with LLLT [34] or reported in the literature [35]. On the contrary, Frigo et al. irradiated melanoma in vitro and in vivo by LLLT and no statistically significant difference observed between controls and laser-irradiated groups for cell proliferation in vitro [36]. On the other hand, tumor mass was significantly higher at doses $1050 \mathrm{~J} / \mathrm{cm}^{2}$ when compared with control. Investigators observed that the high dose $(1050 \mathrm{~J} /$ $\mathrm{cm}^{2}$ ) produced a significant increase in tumor mass volume in in vivo and considerable histological alterations which indicate worsening of the cancer; on the other hand, low dose of $150 \mathrm{~J} / \mathrm{cm}^{2}$ did not induce any changes. Frigo et al. proved that LLLT may not cause cancer if its energy density is very low because no mutational effects can result from light with wavelengths in the red or infrared range and of doses used within LLLT [36]. However, irradiation over known or suspected areas of malignancies should be avoided. We will surely need more studies to give us more answers about laser treatment with cancer patients.

Additionally, we would like to mention that so far, more than 2000 clinical studies have been conducted on the use of LLLT in patients who do not have skin cancer, and in all of these studies, no mutational effects have ever been observed resulting from therapy with wavelengths in the visible or infrared range, in doses used within laser therapy. However, patients who receive ultraviolet (UV) light treatments are at higher risk of premature aging of the skin and of developing skin cancer. Patients must also take care to limit or eliminate their exposure to other sources of UV radiation, especially if they are taking a psoralen compound in addition to receiving the UV treatments.

\section{Conclusions}

The present study showed that LLLT significantly enhanced the viability, proliferation, and migration of normal cultured human melanocytes. We observed that blue and red lasers at low energy densities significantly enhanced the viability, proliferation, and migration of melanocytes. However, a UV laser exerted similar effects at 0.5 and $1.0 \mathrm{~J} / \mathrm{cm}^{2}$ only. Additionally, the blue laser was the best among the three lasers. In contrast, at higher energy densities, all three lasers were ineffective. These results may have clinical implications for vitiligo patients and other skin diseases. LLLT does not have any harmful effects during irradiation process. Additionally, LLLT is non-ionizing radiation and will not induce cancer, damage to skin, or damage to tissues or DNA. Further investigations are required to understand the role of growth factors and cytokines in the obtained results.

Acknowledgments This project was supported by NSTIP strategic technologies programs, number (10-MED1222-02) in the Kingdom of Saudi Arabia.

\section{References}

1. Whitton ME, Ashcroft DM, Barrett CW et al (2007) Interventions for vitiligo [systematic review]. Cochrane database of systematic reviews (3)

2. Avci P, Gupta A, Sadasivam M et al (2013) Low-level laser (light) therapy (LLLT) in skin: stimulating, healing, restoring. Semin Cutan Med Surg 32(1):41-52

3. Shaffrali FCG, Gawkrodger DJ (2000) Management of vitiligo. Clin Dermatol 25:575-579

4. Gasparyan VC (2000) Method of determination of aortic valve parameters for its reconstruction with autopericardium: an experimental study. J Thorac Cardiovasc Surg 119:386-387

5. Rochkind S, Rousso M, Nissan M et al (1989) Systemic effects of low-power laser irradiation on the peripheral and central nervous system, cutaneous wounds and burns. Lasers Surg Med 9:174-182

6. AlGhamdi KM, Kumar A, Moussa NA (2012) Low-level laser therapy: a useful technique for enhancing the proliferation of various cultured cells. Lasers Med Sci 27(1):237-249

7. Barboza CA, Ginani F, Soares DM et al (2014) Low-level laser irradiation induces in vitro proliferation of mesenchymal stem cells. Einstein (Sao Paulo) 12(1):75-81

8. Liao X, Xie GH, Liu HW et al (2014) Helium-neon laser irradiation promotes the proliferation and migration of human epidermal stem cells in vitro: proposed mechanism for enhanced wound re-epithelialization. Photomed Laser Surg 32(4):219-225

9. Tuby H, Maltz L, Oron U (2007) Low-level laser irradiation (LLLI) promotes proliferation of mesenchymal and cardiac stem cells in culture. Lasers Surg Med 39:373-378

10. Lan CC, Wu CS, Chiou MH et al (2009) Low-energy helium-neon laser induces melanocyte proliferation via interaction with type IV collagen: visible light as a therapeutic option for vitiligo. $\mathrm{Br} \mathrm{J}$ Dermatol 161:273-280

11. Lerner AB, Halaban R, Klaus SN et al (1987) Transplantation of human melanocytes. J Invest Dermatol 89:219-224 
12. Eduardo Fde P, Bueno DF, de Freitas PM et al (2008) Stem cell proliferation under low intensity laser irradiation: a preliminary study. Lasers Surg Med 40(6):433-438

13. Hou JF, Zhang H, Yuan X et al (2008) In vitro effects of low-level laser irradiation for bone marrow mesenchymal stem cells: proliferation, growth factors secretion and myogenic differentiation. Lasers Surg Med 40(10):726-733

14. Mvula B, Mathope T, Moore T et al (2008) The effect of low level laser irradiation on adult human adipose derived stem cells. Lasers Med Sci 23(3):277-282

15. Kim HK, Kim JH, Abbas AA et al (2009) Red light of $647 \mathrm{~nm}$ enhances osteogenic differentiation in mesenchymal stem cells. Lasers Med Sci 24(2):214-222

16. Saliba EN, Foreman H (1990) Low power lasers. In: Prentice WE (ed) Therapeutic modalities in sport medicines. Times Mirror Mosby, St Louis, pp 185-188

17. Ausubel R, Brent R, Kingston RE (1994) Short protocols in molecular cloning, 4th edn. Wiley, New York

18. Liang C, Park AY, Guan J (2007) In vitro scratch assay: a convenient and inexpensive method for analysis of cell migration in vitro. Nature Prot 2:329-333

19. Mvula B, Moore TJ, Abrahamse H (2010) Effect of low-level laser irradiation and epidermal growth factor on adult human adiposederived stem cells. Lasers Med Sci 25(1):3-9

20. Karu TI (1998) Primary and secondary mechanisms of the action of monochromatic visible and near infrared radiation on cells. In: The science of low-power laser therapy. Gordon and Breach Science, Amsterdam

21. Smith K (1991) Light and life: the photobiological basis of the therapeutic use of radiation from lasers. In: Progress in laser therapy: selected papers from the October 1990 ILTA Congress. Wiley, New York

22. Karu TI (2003) Biomedical photonics handbook. Low-power laser therapy. CRC Press LLC, Moscow

23. Kreisler M, Christoffers AB, Al-Haj H et al (2002) Low-level 809$\mathrm{nm}$ diode laser-induced in vitro stimulation of the proliferation of human gingival fibroblasts. Lasers Surg Med 30(5):365-369
24. Moore P, Ridgway TD, Higbee RG et al (2005) Effect of wavelength on low-intensity laser irradiation-stimulated cell proliferation in vitro. Lasers Surg Med 36(1):8-12

25. Pinheiro AL, Brugnera Júnior A, Zanin FA (2010) Aplicação do laser na odontologia. São Paulo: Santos

26. Karu TI (1987) Photobiological fundamentals of low-power laser therapy. J Quantum Electron 23:1703-1717

27. Wilden L, Karthein R (1998) Import of radiation phenomena of electrons and therapeutic low-level laser in regard to mitochondrial energy transfer. J Clin Laser Med Surg 16(3):159-165

28. Yoshida H, Kunisada T, Grimm T et al (2001) Review: melanocyte migration and survival controlled by SCF/c-kit expression. J Invest Dermatol Symp Proc 6:1-5

29. Norris DA, Horikawa T, Morelli J (1994) Melanocyte destruction and repopulation in vitiligo. Pig Cell Res 7:193-203

30. Cui J, Shen LY, Wang GC (1991) Role of hair follicles in the repigmentation of vitiligo. J Invest Dermatol 97:410-416

31. Staricco RG, Miller-Milinska A (1962) Activation of the amelanotic melanocytes in the outer root sheath of hair follicle following ultraviolet rays exposure. J Invest Dermatol 39:163-164

32. Fitzpatrick TB (1997) Mechanisms of phototherapy of vitiligo. Arch Dermatol 133:1591-1592

33. Nordlund JJ, Ortonnc JP (1992) Vitiligo and depigmentation. Curr Probl Dermatol 4:5-30

34. Yu HS, Wu CS, Yu CL et al (2003) Helium-neon laser irradiation stimulates migration and proliferation in melanocytes and induces repigmentation in segmental-type vitiligo. J Invest Dermatol 120: 56-64

35. Potinen PJ (1992) The physics of laser. In: Potinen PJ, ed. Low level laser therapy as a medical treatment modality. Tampere: Art Urpo Ltd, pp 17-44

36. Frigo L, Juliana SSL, Giovani MF et al (2009) The effect of lowlevel laser irradiation (In-Ga-Al-AsP - $660 \mathrm{~nm}$ ) on melanoma in vitro and in vivo. BMC Cancer 9:404-411 